\title{
Country mapping: Senegal
}

\author{
Babacar Mane \\ Population Council \\ Nafissatou Diop \\ Population Council \\ Nancy Termini LaChance \\ Population Council \\ Saumya RamaRao \\ Population Council \\ Heather Clark \\ Population Council
}

Follow this and additional works at: https://knowledgecommons.popcouncil.org/departments_sbsr-rh

Part of the Demography, Population, and Ecology Commons, Family, Life Course, and Society

Commons, International Public Health Commons, Maternal and Child Health Commons, Obstetrics and Gynecology Commons, and the Women's Health Commons

How does access to this work benefit you? Let us know!

\section{Recommended Citation}

Mane, Babacar, Nafissatou Diop, Nancy Termini LaChance, Saumya RamaRao, and Heather Clark. 2012. "Country mapping: Senegal," Progesterone Vaginal Ring Technical Report. New York: Population Council. 


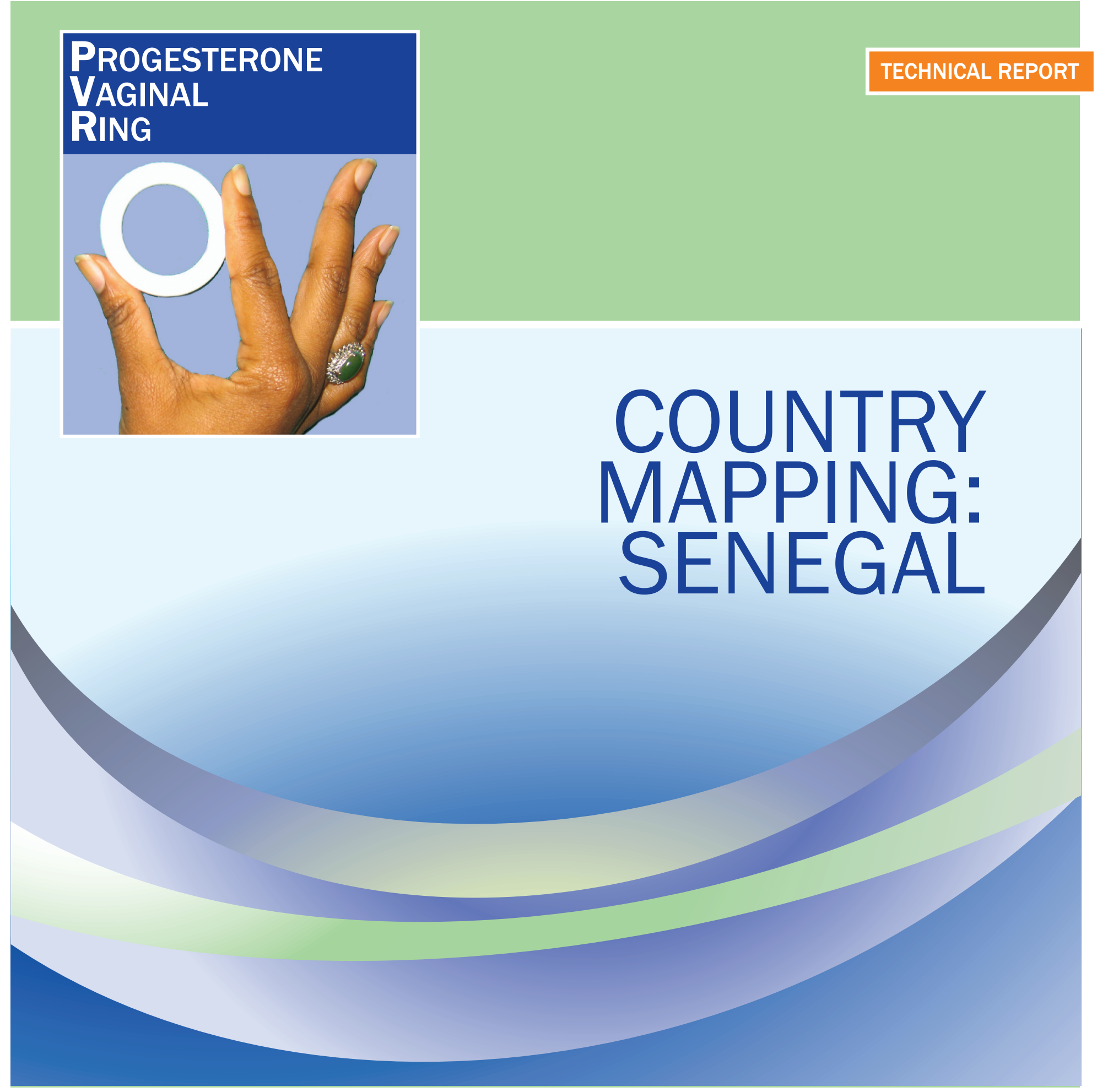

BABACAR MANÉ NAFISSATOU DIOP NANCY TERMINI SAUMYA RAMARAO HEATHER CLARK

DECEMBER 2012

(P) Population Council 


\section{Q. Population Council}

The Population Council confronts critical health and development issues-from stopping the spread of HIV to improving reproductive health and ensuring that young people lead full and productive lives. Through biomedical, social science, and public health research in 50 countries, we work with our partners to deliver solutions that lead to more effective policies, programmes, and technologies that improve lives around the world. Established in 1952 and headquartered in New York, the Council is a nongovernmental, nonprofit organization governed by an international board of trustees.

Population Council

One Dag Hammarskjold Plaza

New York, NY 10017

www.popcouncil.org

\section{Acknowledgments}

This material is for a research project funded by the Bill \& Melinda Gates Foundation. The information contained within does not necessarily reflect positions or policies of the Bill \& Melinda Gates Foundation.

(C) 2012 The Population Council, Inc. 


\section{TABLE OF CONTENTS}

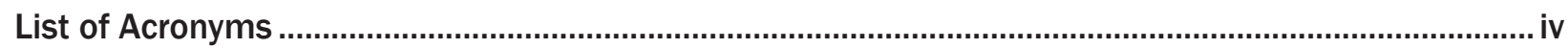

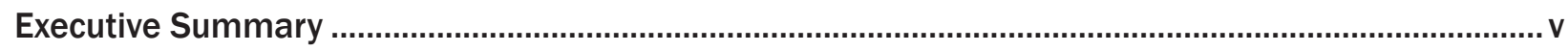

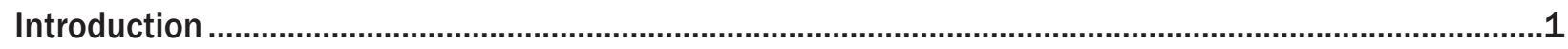

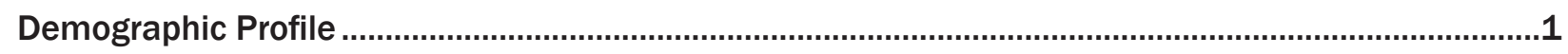

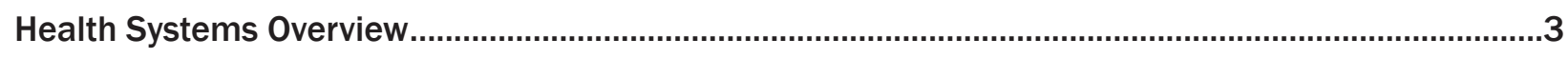

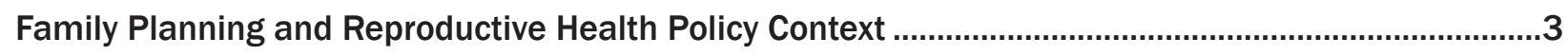

Environment Regarding Hormonal Contraceptives \& HIV Risk ............................................................4

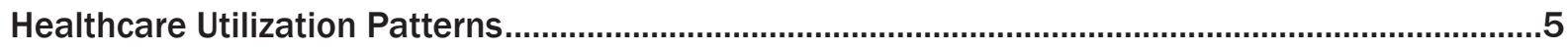

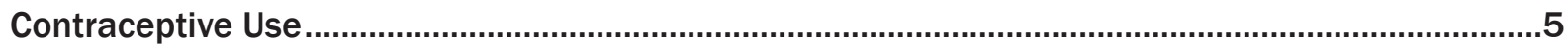

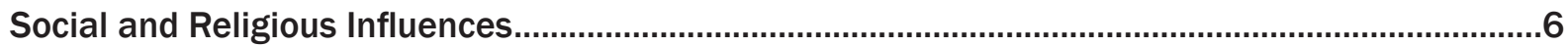

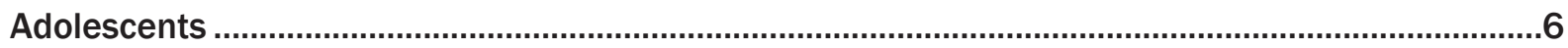

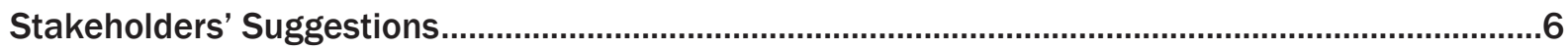

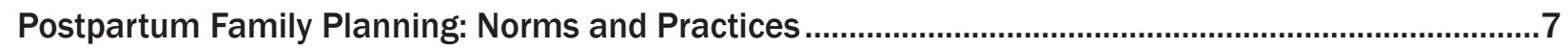

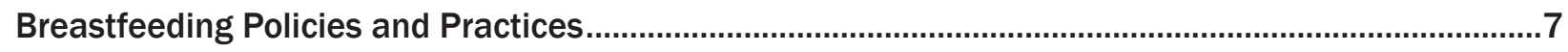

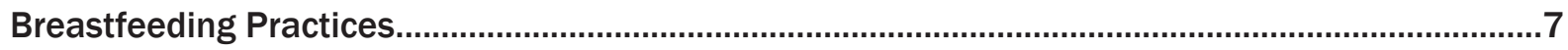

National Breastfeeding and Formula Policy ..................................................................................

Securing Contraceptive Commodities and Getting Them to Market...................................................

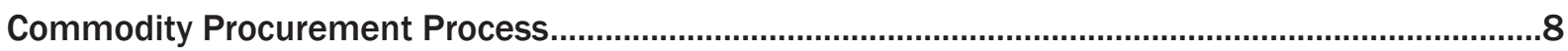

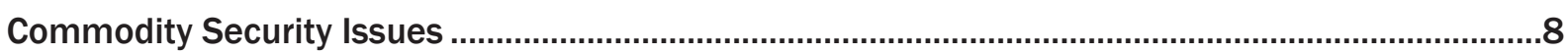

Regulatory Framework for New Contraceptives and Health Products............................................8

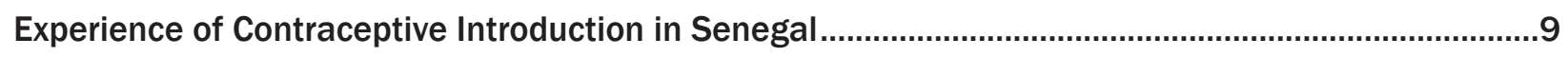

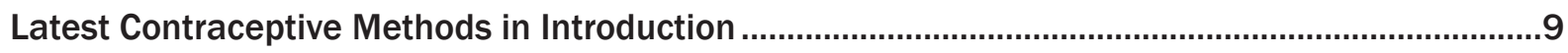

Lessons learned from experiences of contraceptive introduction ............................................... 10

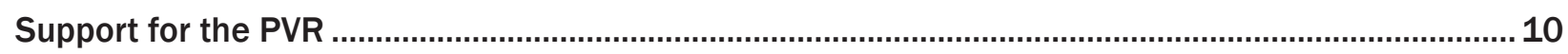

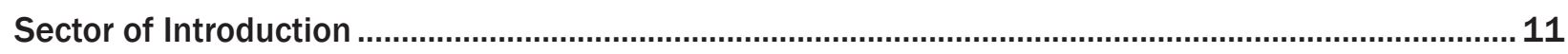

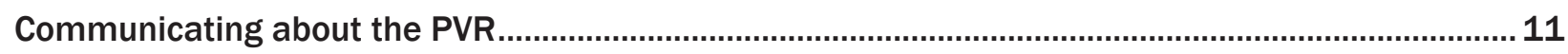

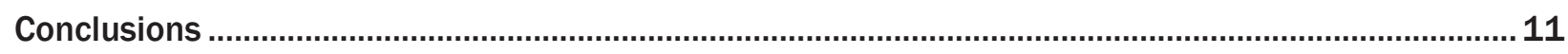

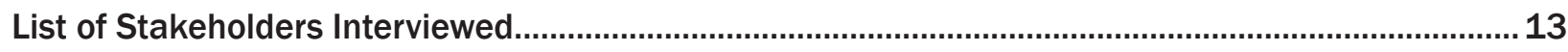

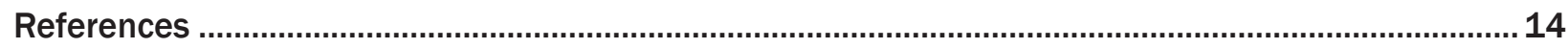




\section{ACRONYMS}

ASBEF

Association Sénégalaise pour le Bien

Etre Familial/Senegalese Association for

Family Welfare

CEFOREP Centre de Formation et de Recherche en Santé de la Reproduction/Regional Center for Training, Research and Advocacy in Reproductive Health

CNERS National Ethics Committee for Health Research

CPR Contraceptive Prevalence Rate

DHS Demographic and Health Survey

DMPA Depot Medroxyprogesterone Acetate

DPM Direction de la Pharmacie et du Médicament/Directorate of Pharmacy and Medicine*

DPP Déclaration de Politique de Population/ Population Policy Declaration

DSRSE Direction de la Santé de la Reproduction et de la Survie de l'Enfant/Directorate of Reproductive Health and Child Survival

EC Emergency Contraception

FP Family Planning

HIV/AIDS Human Immunodeficieny Virus/ Acquired Immunodeficieny Syndrome

ICT Information and Communication Technology

IM Intramuscular
ISSU Initiative Sénégalaise de Santé Urbaine/ Senegalese Urban Health Initiative

IUCD Intrauterine Contraceptive Device

LAM Lactational Amenorrhea Method

$\mathrm{MCH} \quad$ Maternal and Child Health

MDG Millennium Development Goals

MIA Market Introduction Authorization

MICS Multiple Indicators Cluster Survey

$\mathrm{MOH} \quad$ Ministry of Health

NGO Nongovernmental Organization

PLWHA People Living With HIV/AIDS

PNA Pharmacie Nationale d'Approvisionnement

PRA Pharmacie Régionale d'Approvisionnement

PVR Progesterone Vaginal Ring

$\mathrm{RH} \quad$ Reproductive Health

SDP Service Delivery Point

STI Sexual Transmitted Infections

TFR Total Fertility Rate

UNFPA United Nations Population Fund

USAID United States Agency for International Development

WHO World Health Organization

\footnotetext{
* Previously known as Directorate de la Pharmacie et des Laboratoires (Directorate of Pharmacy and Laboratories). The Directorate was recently split in two: the Directorate of Pharmacy and Medicines, and the Directorate of Laboratories. The PVR study is concerned with the DPM.
} 
The Population Council has embarked on a three-year project to explore the acceptability of the progesterone vaginal ring (PVR) among women in sub-Saharan Africa and the process for its potential introduction. From February to May 2012, assessments were undertaken in study countries in sub-Saharan AfricaKenya, Nigeria, and Senegal-to map the existing landscape of family planning programs and new contraceptive technologies in an effort to identify national priorities and assess the level of interest in the PVR among stakeholders and to design appropriate preintroductory activities.

Research teams employed three approaches to develop each country report: (1) a review of available data; (2) a desk review of documents, project reports, and policy guidelines; and (3) key informant interviews. Interviews were held with representatives of key government, regulatory, and development agencies; social marketing organizations; research institutions; advocacy groups; private sector stakeholders; policymakers; and civil society members.

This country mapping exercise confirms that Senegal is a promising context for the introduction of the PVR. The government is committed to repositioning family planning and has created an enabling environment. There are also various encouraging sociocultural trends which suggest potential for acceptance of the PVR, including the fact that birth spacing is already an accepted norm in Senegal.
Based on the information gathered, input from the stakeholder interviews, and previous experiences of contraceptive introduction, some key accompanying measures will need to be taken to ensure proper execution of the acceptability study and subsequent introductory efforts, including involving the Ministry of Health early, developing and disseminating literature on the PVR and project in French, and establishing an appropriate communication plan to name a few.

Interviewees emphasized that the PVR must be an integral part of the national family planning program. Therefore, social resistance and perceived religious barriers to use must be taken into account in the acceptability study and future possible introduction of the PVR.

The PVR has the capability of improving family planning practices of postpartum women across diverse spatial, demographic, and socioeconomic settings. By extension, women's use of the ring can improve the health of her whole family. Its innovative, long- and mid-acting, user-controlled design will introduce a unique dimension to the current method mix and is a promising prospect for provision at the community level in Senegal. 


\section{INTRODUCTION}

While progress made in recent decades in fertility reduction has been impressive, still up to 222 million women in the developing world report an unmet need for contraception (Singh and Darroch 2012). Part of the challenge of addressing current levels of unmet need is the limited use of contraception by women during the first six to 12 months postpartum and the discontinuation rates of about half of all users abandoning their methods six months after adopting them. Both issues lead to limited success in effective birth spacing, which can then negatively impact maternal and infant health. New contraceptive methods are needed that offer greater ease of use, are women-controlled, and do not require significant health infrastructure or medical provider involvement for service delivery. One such method is the progesterone vaginal ring (PVR), a user-controlled contraceptive that, according to clinical trial data, is safe and effective for breastfeeding women.

The Population Council has embarked on a threeyear project to explore the acceptability of the PVR among women in sub-Saharan Africa and the process for its potential introduction. From February to May 2012, assessments were undertaken in proposed project countries in sub-Saharan Africa-Kenya, Nigeria, and Senegal-to map the existing landscape of family planning programs and new contraceptive technologies in order to identify national priorities and assess the level of interest among stakeholders in the PVR and to design appropriate pre-introductory activities. In Senegal, the research team employed three approaches to develop the country report: a review of available data; a desk review of documents, project reports, and policy guidelines; and key informant interviews. Interviews were held with representatives of key government, regulatory, and development agencies; social marketing organizations; research institutions; advocacy groups; private sector stakeholders; policymakers; and civil society members. The report begins by describing the country's demographics and fertility rates, and then provides an overview of the health systems before elaborating on the reproductive health policy context with an emphasis on family planning policy and programs. Finally, the report explores potential support to PVR as a new contraceptive option that could be added to the method mix of the country's national family planning program.

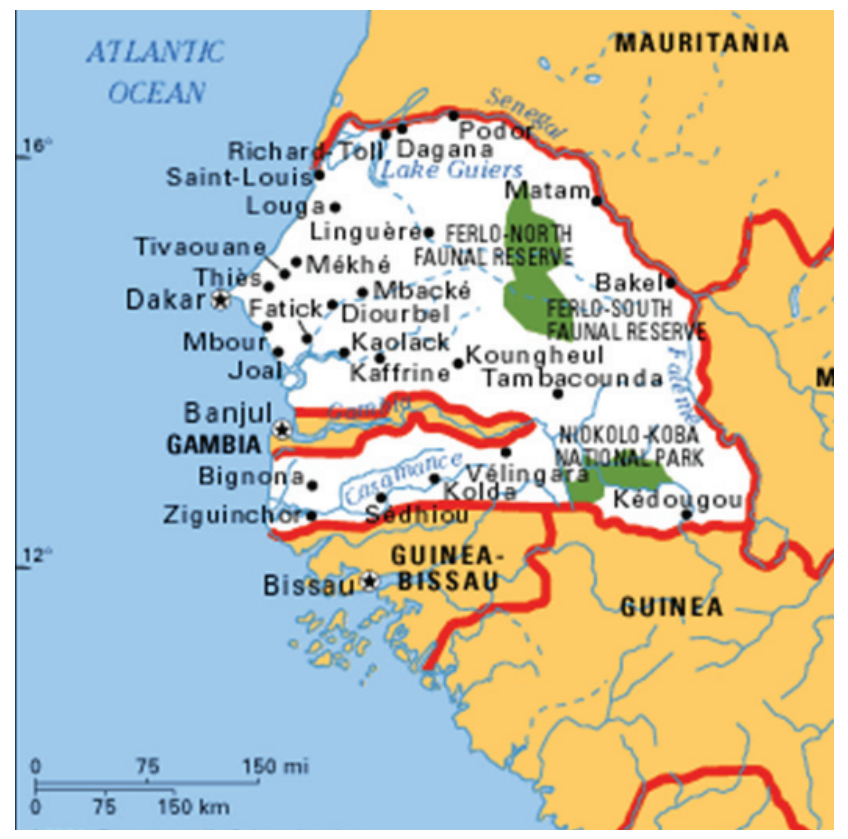

\section{DEMOGRAPHIC PROFILE}

According to the Agence Nationale de la Statistique et de la Démographie (ANSD 2012), the projected population of Senegal in 2012 is over 13.2 million people. This represents a near doubling of the population within 25 years; in 1988, the population was 6.9 million (ANSD 2005). The urban population accounts for nearly $42 \%$ of total population. The Dakar region, which only covers

\section{DEMOGRAPHIC SNAPSHOT}

\begin{tabular}{|c|c|}
\hline POPULATION: & 13.2 million \\
\hline GROWTH RATE: & $2.5 \%$ \\
\hline TOTAL FERTILITY RATE: & 5 children per woman \\
\hline $\begin{array}{l}\text { CONTRACEPTIVE } \\
\text { PREVALENCE RATE: }\end{array}$ & $12 \%$ \\
\hline $\begin{array}{l}\text { UNMET NEED FOR FP } \\
\text { FOR MARRIED WOMEN: }\end{array}$ & $29 \%$ \\
\hline $\begin{array}{l}\text { MATERNAL } \\
\text { MORTALITY RATIO: }\end{array}$ & $392 / 100,000$ \\
\hline $\begin{array}{l}\text { INFANT } \\
\text { MORTALITY RATE: }\end{array}$ & $47 / 1,000$ \\
\hline $\begin{array}{l}\text { BIRTHS OCCURRING } \\
\text { WITHIN } 24 \text { MONTHS } \\
\text { AFTER PRIOR BIRTH: }\end{array}$ & $18 \%$ \\
\hline HIV INCIDENCE: & $0.7 \%$ \\
\hline
\end{tabular}


$0.3 \%$ of the country, includes $23 \%$ of the total population ( $75 \%$ of the urban population). With a growth rate of approximately $2.5 \%$ per year, the share of young people in Senegal's population is still growing; as of 2011, over half of the population was under the age of 20 . This can be attributed to long-sustained high rates of fertility due to low use of contraceptive methods (12\% for women in union), and a steady decline in infant mortality. The total fertility rate (TFR) is currently 5 children per woman (at an average of 6 per woman in rural areas, and 3.9 per woman in urban areas), and the infant mortality rate dropped from $68 \%$ in $1997-1998$ to $47 \%$ in 2010 2011 (ANSD and ICF International 2012).

Fertility rates in Senegal have been on the decline since the first Demographic and Health Survey (DHS) was taken in 1986, dropping from 6.4 children per woman in 1986 to 5.0 children per woman in 2010-2011.

Figure 1 presents the downward trend of the TFR over time. However, clear differences appear between fertility rates for different socioeconomic groups of women. For example, women in urban areas have a TFR of 3.9 compared to 6.0 for rural women. Educated women have 2.9 children on average compared to 5.8 for women with no education. Also, women in the richest quintile have a TFR twice as small as their counterparts in the poorest quintile (3.3 vs. 7.0) (ANSD and ICF International 2012).

High fertility rates are explained in part by the common practice of early marriage, which results in early entry into sexual and reproductive activity. The 2010-2011 Demographic and Health Survey-Multiple Indicator Cluster Survey (DHS-MICS) indicated that two in three women and four in 10 men were married.

\section{FIGURE 1: TOTAL FERTILITY RATE}

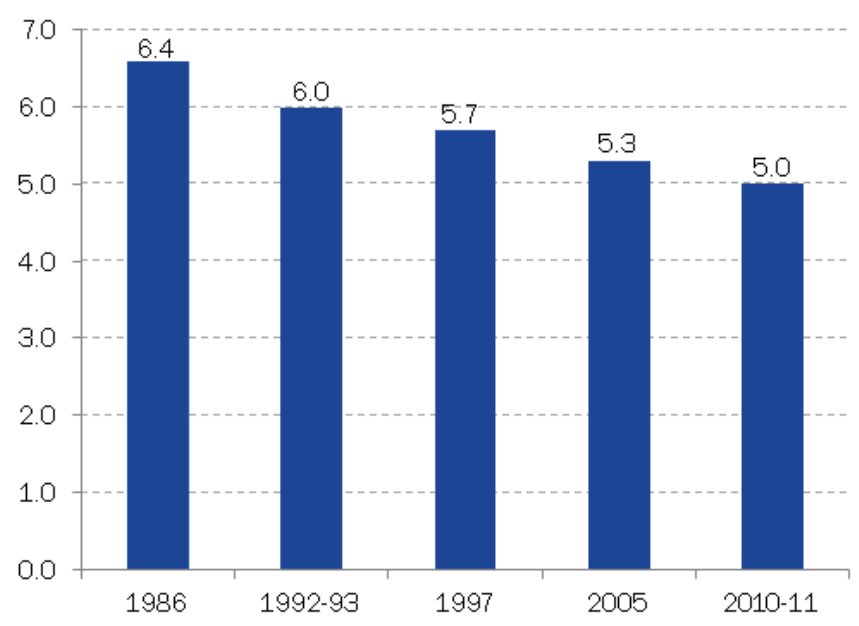

Source: ANSD. 2012. Senegal 2010-2011 DHS-MICS. Final report
Sixteen percent of Senegalese girls are married by the age of 15 , with $40 \%$ married by the age of 18 . Girls from the poorest or rural households generally marry earlier (at median ages of 16.5 and 17.7, respectively) and girls from the richest or urban households tend to marry later (23.2 and 21.5, respectively). The median age at first marriage is 19.3 years for women. The median age at sexual onset is 20.5 years for urban women and 17.5 years for rural women. Furthermore, $35 \%$ of married women were in polygamous marriages, although the practice is more common in rural areas.

Despite the fact that the median age at first birth for females is 21 years old, $16 \%$ of female DHS-MICS respondents aged 15-19 were already mothers, and $3 \%$ were pregnant with their first child. The high proportion of teenage mothers is even more dramatic in rural areas-25\%, as compared with $12 \%$ in urban areas.

TFR decreases with increased education level (Figure 2). However, although significant efforts have been made in the field of education, schooling levels remain low for both males and females. Fifty-eight percent of women and $39 \%$ of men reported having had no formal education. Furthermore, only $3 \%$ of female and $6 \%$ of male respondents had actually completed secondary education or higher.

Given the large population of uneducated Senegalese and the high prevalence of marriage ( $66 \%$ of women of reproductive age are married), it is all the more critical that easy-to-use, safe, and effective family planning methods be made more accessible in Senegal. One of the many developmental challenges associated with the dual problem of early marriage and lack of female education is that, consequently, Senegalese

\section{FIGURE 2: TFR BY EDUCATION}

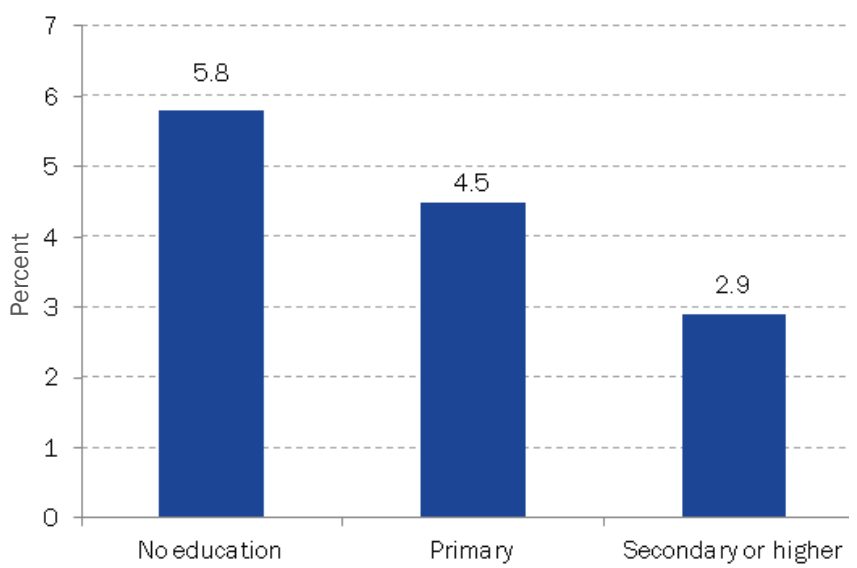

Source: ANSD. 2012. Senegal 2010-2011 DHS-MICS. Final report 
women often lack the ability to negotiate safe sex within their marriages, including the use of modern contraception methods. This decreases the chances that a woman can practice postpartum family planning in order to space her pregnancies.

Interestingly, the median birth interval in Senegal is 34 months, which is generally considered to be healthy spacing (although the WHO recommends spacing of 3-5 years). However, this figure does not reveal the wide range of intervals experienced; countrywide, 18\% of infants were born fewer than two years after the previous birth. With an estimated maternal mortality rate of 392 per 100,000 live births for the 10-year period before the 2010-2011 DHS-MICS, the promotion of postpartum family planning to prevent maternal death due to closely-spaced births is an important avenue for improving the health of women and infants in Senegal.

\section{HEALTH SYSTEMS OVERVIEW}

The provision of reproductive health $(\mathrm{RH})$ services within the national health system in Senegal is hierarchically based on the following four levels:

- Primary (community) level: health huts and health posts;

- Secondary (district) level: health centers;

- Tertiary (regional) level: regional hospitals;

- National (central) level: referral hospitals and public central administration.

All levels implement activities developed in the yearly operation plan. However, specific responsibilities and integrated packages of services are defined per level, for example:

- The district level oversees planning as well as operationalization of the national policy and program with the Service Delivery Points (SDPs).

- The regional level is charged with the coordination, monitoring, and supervision of the national policy implementation by districts. It also contributes to design, coordination, planning, and monitoring activities at the regional level.

- The national level leads the design, coordination, planning, and monitoring of national guidelines The price for all commodities is also set at this level.
Except for health huts, services at each level of the hierarchy are provided by doctors, nurses and midwives. Health huts are equipped with community health workers (matrons, Badien Gox, relais). The private sector and NGOs play an important role in the provision of $\mathrm{RH}$ services. In a district, all SDPs, regardless of sector, respond to the district Head Medical Officer.

The government of Senegal has undertaken a policy of decentralization of health services. This policy focuses on providing services that are accessible geographically and financially, and that are socio-culturally and religiously acceptable. Among others, these activities include : (1) increasing the number of SDPs; (2) providing a minimum package of reproductive health services at health posts; and (3) adjusting the costs of services with the standard of living of the population.

This policy also ensures support to regional level by: (1) strengthening human resources and providers' training; (2) transferring technical and managerial skills; (3) increasing the accountability of stakeholders (including at community level); and (4) supportive supervision.

\section{FAMILY PLANNING AND REPRODUCTIVE HEALTH POLICY CONTEXT}

The introduction of family planning into Senegal first began in 1970 in the private sector at the "Croix Bleue" clinic followed in 1975 by local NGOs such as the Senegalese Association for Family Welfare (ASBEF). The commitment of public authorities in favor of family planning began in the 1980s with the execution of two major projects: the Family Health and Population Project funded by USAID and the Family Welfare Project funded by UNFPA.

Senegalese national authorities first adopted an official Declaration of Population Policy (DPP) in 1988. The policy aimed to reduce the population growth rate and the number of children per women. Family planning is the primary strategy outlined for achieving this objective. The objectives of this policy are to:

1. Reduce morbidity and mortality, particularly among mothers and children by strengthening $\mathrm{RH}$ programs;

2. Reduce fertility rate and population growth rate;

3. Harmonize population growth with development requirements; and 
4. Improve the integration of the population variable in the formulation and implementation of macroeconomic policies and multi-sectoral strategies.

The DPP was updated in 1995 and again in 2005 in order to align the policy with the international agenda for the Millennium Development Goals (MDGs). The MDGcentric goals were reiterated and updated in several subsequent policy documents, including the "Roadmap for accelerating the multi-sectoral fight against maternal and neonatal mortality" Government of Senegal and the Strategic Action Plan on Reproductive Health 2012-2015.

In addition to setting a favorable political environment, the government adopted the 2005 Law on Reproductive Health (Government of Senegal 2005) which governs the activities within the $\mathrm{RH}$ program. The Law also outlines various rights and requirements designed to regulate the types and quality of $\mathrm{RH}$ health services, including family planning.

In 2012, the Ministry of Health elevated the office in charge of public reproductive health activities in Senegal to the Directorate of Reproductive Health and Child Survival (DSRSE). The new Directorate developed a Family Planning Action Plan for the period 2012-2015. This ambitious plan states a goal of increasing CPR from $12 \%$ in 2012 to $27 \%$ by 2015 . This goal will require the recruitment of 350,000 new users of contraceptive methods, with a contribution of 125,000 new clients by the public sector, 100,000 new clients by the private sector, and 125,000 new clients by the community level (Government of Senegal 2006). Priority actions to operationalize the Action Plan will address:

"Broadening the range of contraceptive methods is an opportunity to recruit potential clients who have not been satisfied with the method mix currently available."

-OFFICIAL AT THE MINISTRY OF HEALTH
- Advocacy for FP resource mobilization and greater involvement of the private sector;

- Implementation of an FP communications plan;

- Strengthening of services in the public sector by improving logistics system ("push model”), recruiting qualified staff, and supervising activities;

- Strengthening of services offered in the private sector; and

- Strengthening of community-level FP activities by introducing new initiatives to further improve access to FP services.

Targeting women with unmet need for family planning has become a key strategy for increasing CPR. The DSRSE has engaged in multiple initiatives over the years, including: (1) task-shifting to enable head nurses to provide long-acting methods (Jadelle and IUCDs) in health posts, and (2) community-level introduction of the oral contraceptive pill by matrons in health huts. These initiatives will help diversify the supply of and improve access to contraceptive methods all the way to the most peripheral levels throughout the country. In addition, during the next few years, efforts will be directed toward increasing method mix by promoting new contraceptive methods.

\section{Environment Regarding Hormonal Contraceptives and HIV Risk}

A 2007 set of protocols released by the DSRSE, "Protocoles des services de santé de la Reproduction," clarified that the department's approach to the question of hormonal contraceptive involvement with HIV risk is one of alignment with WHO directives concerning the issue.

In accordance with WHO guidelines, protocols for family planning service provision integrate STI and HIV/ AIDS services. During family planning counseling, providers are required to emphasize the need for users to protect themselves against HIV and other STIs. For each method, the provider must inform clients whether it can protect them against HIV or STIs. Moreover, in order to take into account the family planning needs of people living with HIV/AIDS (PLWHA), the DSRSE and the HIV/ AIDS Division within the Ministry of Health are collaborating to introduce FP services in PLWHA outpatient treatment centers. 


\section{Healthcare Utilization Patterns}

Contraceptives (specifically hormonal-based methods) are available to the public through nationally integrated family planning and maternal and child health $(\mathrm{MCH})$ programs. That is, clients can obtain family planning methods through either $\mathrm{MCH}$ or family planning clinics. In Senegal, family planning is considered a major and transversal intervention for improving maternal and child health.

While the majority of users (83\%) obtain their contraceptive methods from public health facilities, national policy orientation promotes the involvement of private and nonprofit sectors as essential sources for providing family planning at all levels. Twelve percent of clients obtain services from private facilities, and the remainder obtain them from other sources (ANSD and ICF International 2012). In most clinical settings, a combination of skilled providers (nurses, midwives, and doctors) offer family planning services. Generally, initial family planning counseling is offered by trained communitybased workers.

\section{Contraceptive Use}

It is evident that long-acting contraceptive methods are highly underutilized in Senegal. As part of its plan to revitalize use of modern contraceptive methods, the DSRSE will work to ensure a broad range of contraceptive options, but will focus specifically on promoting longacting methods. According to the Family Planning Office Manager of the DSRSE, the office is also seeking to promote user-controlled methods which reduce the need for systematic interventions of a health care provider, a strategy which has been termed "demedicalisation" of family planning service provision.

Although $90 \%$ of females and $93 \%$ of male respondents to the 2010-2011 DHS-MICS indicated knowledge of at least one modern method of family planning (most commonly the oral contraceptive pill and male condoms), usage remains relatively low (13\% for married women) and unequally distributed across socioeconomic groups (see Figure 3).

The low usage is at odds with the declared family planning desires of women: $21 \%$ of married women do not want any more children, and $38 \%$ want to wait at least two years before their next birth (ANSD and ICF International 2012). ${ }^{4}$ Overall, unmet need for family planning among currently married women is nearly $30 \%$, a rate that varies little between rural and urban areas
FIGURE 3: CURRENT USE OF FAMILY PLANNING BY MARRIED WOMEN

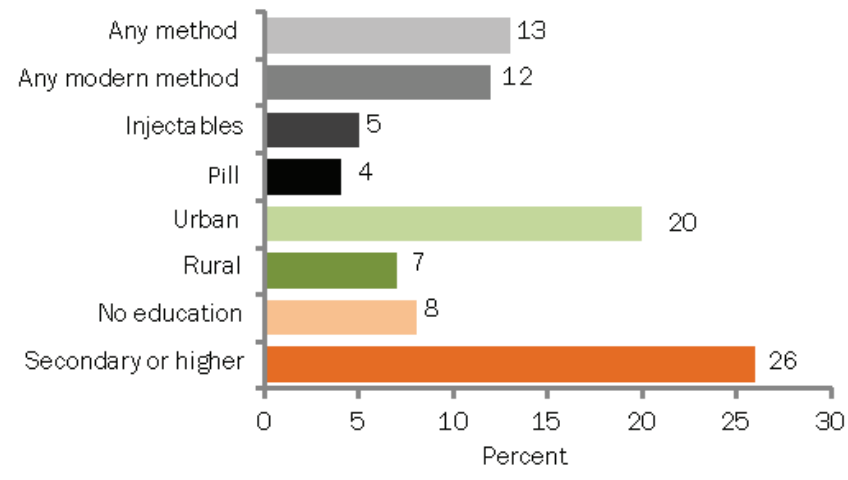

Source: Senegal 2010-2011 DHS-MICS. Key findings.

(29\% vs. 30\%, respectively). ${ }^{4}$ A survey conducted by the Senegal Urban Health Initiative (ISSU) across four urban centers indicated similar findings between income groups (http://www.urbanreproductivehealth.org/sites/ mle/files/Data_Handout_French_O.pdf).

The most common contraceptive methods offered by the National Program are oral contraceptive pills, injectables, male and female condoms, the IUCD, and the implant ). In the 2010-2011 DHS-MICS, the most common methods actually used by women, however, are pills (2.9\%) and injectables (3.7\%) in all places of residence, though in different proportions. In urban settings the pill is used by $7.5 \%$ of women and injectables are used by $7.7 \%$, whereas in rural areas the pill is used by $1.7 \%$ of women and injectables are used by $3.5 \%$. As shown on Figure 4, the survey conducted by ISSU also found pills and injectables to be the most commonly used methods in the 4 urban sites. It also indicated

\section{FIGURE 4: MODERN FAMILY PLANNING METHOD MIX}

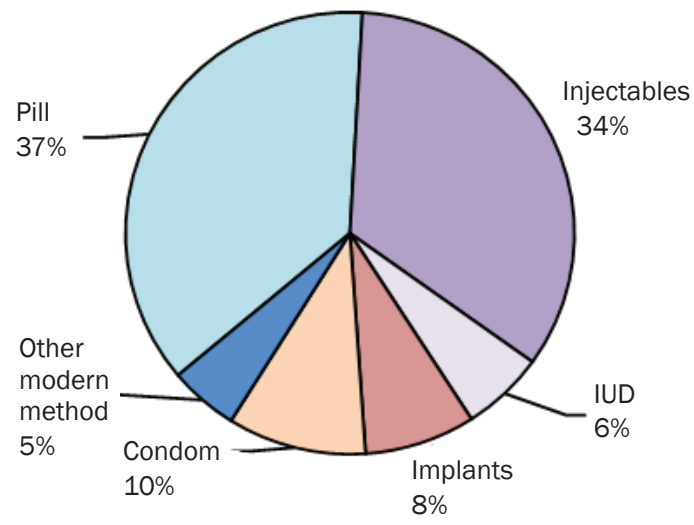

Source: ISSU, MLE and IntraHealth survey in four urban centers. 
that there was more demand for long-acting methods (Jadelle at $8 \%$ and IUCDs at 6\%) in these urban settings than at the national level.

Until recently, women preferred injectables or the pill because they are easy to conceal, easy to use, and appropriate for facilitating the local norm of two-year birth spacing. Providers themselves often preferred providing these methods because they are less demanding in terms of work time and resource mobilization. Additionally, until recently, long-acting methods were not available at health posts. However, recent efforts for repositioning FP with a focus on longer acting methods seem to lead to a preference shift toward methods such as Jadelle (five years).

In 2000, emergency contraception (EC) was introduced into the national family planning program in both the private and the public sector. This effort, conducted by the DSRSE with support from the Population Council, led to the full integration of EC into national guidelines. However, EC usage remains low. From the demand side, socio-cultural and religious barriers are the main factors limiting its promotion and use. From the supply side, service provider attitudes and practices are often unfavorable toward delivering EC.

\section{Social and Religious Influences}

Various surveys explore the nature of family and community influences on contraceptive preferences, perceptions, and challenges to access (Intrahealth International 2012). For example, in the ISSU study, $18 \%$ of women not utilizing modern contraception indicated that they were either personally opposed to it, or believed that their husbands were opposed to it. Fourteen percent of female respondents feared potential side effects or health problems with the use of modern contraception, whereas nearly half of married male respondents believed that family planning is harmful to women's health.

Ninety-four percent of Senegalese are Muslim while $4 \%$ are Christian and $2 \%$ animist. More than $90 \%$ of male and female responses to the ISSU survey agreed or strongly agreed that only God can decide the number of children a couple will have. Collaboration with Muslim and Christian networks has helped mitigate misinterpretation of the position of religion toward family planning. Furthermore, outreach activities undertaken by a Muslim network contributed to clarifying women's status and rights within Islam and society, including with regard to family planning. Also, over three-quarters of respon- dents ( $79 \%$ of female and $74 \%$ of male respondents) felt that religious leaders should speak more overtly about the role of family planning in religion. But while it is encouraging that the majority of male respondents indicated a willingness to hear more about family planning, the fact remains that the social and economic position of women in Senegal reduces their decisionmaking abilities regarding their reproductive health, even though Senegalese law promotes their right to do so.

\section{Adolescents}

The $2005 \mathrm{RH}$ law establishes the right of adolescents to access quality family planning services. Yet most stakeholders indicate that young people are insufficiently taken into account in the implementation of family planning programs even while the political and legal environments have improved. Cultural norms that prohibit sex before marriage reinforce the stigma of adolescents who want to use the services. In addition, despite improved provider training, young people continue to be stigmatized when attending health facilities. Moreover, inadequate hours and high costs limit adolescents' access to reproductive health services.

Some key stakeholders suggest that improving young people's access to services requires the following measures be taken:

- Implement suitable and appropriate channels of communication, including using Information \& Communication Technologies (ICTs);

- Strengthen youth RH education;

- Broaden the network of youth counseling centers, especially in rural areas; and

- Strengthen the capacity of providers to address the needs of adolescents.

\section{Stakeholders' Suggestions}

Stakeholders interviewed for this mapping exercise emphasized that the PVR must be an integral part of the national family planning program. Therefore, the following social resistance and perceived religious barriers to use that are faced by the program must be taken into account in the acceptability study and future possible introduction of the PVR:

- Disseminate the law on $\mathrm{RH}$;

- Involve men more in FP programs; 
- Integrate FP into the package of services for women and children victims of sexual violence;

- Disseminate religious discourses on the position of Islam and Christianity on FP; and

- Increase the involvement of community actors and journalists in communication about FP.

\section{POSTPARTUM FAMILY PLANNING: NORMS AND PRACTICES}

The norm for birth spacing in Senegal is approximately two years. However, it is important to note that while birth spacing is encouraged, socio-cultural and religious norms are not favorable to birth limitation, which may contribute to the lack of widespread uptake of longacting methods. National family planning programs themselves emphasize birth spacing over limitation as well. Yet although this socio-cultural context is not one that encourages birth limiting, the fact that any kind of spacing between births is acceptable does suggest that successful promotion of postpartum family planning methods such as the PVR and increasing the norms for birth intervals to 3-5 years may in fact be possible.

\section{BREASTFEEDING POLICIES AND PRACTICES}

\section{Breastfeeding Practices}

Breastfeeding is near universal in Senegal, with nearly all (98\%) children ever being breastfed. At 12-17 months of age, $95 \%$ of children are still breastfeeding, although not exclusively. Seventy-one percent of children aged 6-9 months receive complementary foods. The norm for weaning is around two years (the median duration of breastfeeding being approximately 21 months). Yet although Ministry guidelines promote early breastfeeding as a central component of essential neonatal care, and national family planning programs have integrated lactational amenorrhea method (LAM) into their range of promoted methods, only $48 \%$ of children are breastfed in the first hour of life and $89 \%$ are breastfed the day after birth. Further, the 2010-2011 DHS-MICS revealed that $53 \%$ of newborns receive food other than breast milk in the first three days after birth.

\section{BREASTFEEDING IN} SENEGAL

- $98 \%$ of children are ever breastfed

- $39 \%$ of infants ( $<6$ months) are exclusively breastfed

- Norms for weaning: 2 years

Only 39\% of children below six months of age are exclusively breastfed, due in part to a belief in the necessity of early supplementation of breast milk by other foods in the newborn's diet. Introduction of water is one of the key inhibiting factors to strict breastfeeding as many mothers continue to think that water is essential for the child's survival. Moreover, the practice of exclusive breastfeeding is constraining for some women, especially working women and urban and educated women, although labor laws contain provisions to help nursing mothers adhere to the practice.

\section{National Breastfeeding and Formula Policy}

The National Policy for Infant Feeding strongly recommends exclusive breastfeeding until 6 months of age. Thus, the sale of breast milk substitutes for infants younger that six months is prohibited by a ministerial decree signed in 1994. This decree was aimed at health workers, pharmacists, pharmaceutical companies, manufacturers of breast milk substitutes, and manufacturers of mineral water. However, since its enactment, the decree has not been enforced and is not being monitored by the Ministry of Commerce.

For children older than six months, the National Policy promotes the effective implementation of the International Code of Marketing of breast milk substitutes such as formula. This code (although it is not effectively followed) aims to reinforce the accessibility and availability of maternal milk substitute in public and private SDPs including health posts, health centers, and hospitals. 


\section{SECURING CONTRACEPTIVE COMMODITIES AND GETTING THEM TO MARKET}

\section{Commodity Procurement Process}

To streamline the contraceptive supply chain, the Ministry of Health integrated contraceptives into the national list of essential drugs. The current logistics system is organized as follows:

- National Supply Pharmacy (PNA) that controls supply of $\mathrm{RH}$ commodities at the national level, and transfer of these products to the regional level

- Regional Supply Pharmacies (PRA)

- District depots

- Service Delivery Point (SDP) depots

The current supply system is set up as follows:

- SDPs send their orders to the district;

- The district aggregates these orders and sends a global order to the regional level;

- The regional facility transmits the orders from all its districts to the PNA.

Each level is responsible for planning for their commodity needs and orders are made quarterly. Monitoring is ensured by the PNA which delivers products based on the quarterly inventory records tracing the movements of commodities.

The supply system is organized by level to prevent shortages, reduce expiration, and establish coherent contraceptive orders:

- At the PNA level; no more than 12 months and no fewer than six months of supply must be stored at any time;

- At the PRA level, supply storage is permitted for a maximum of six months and a minimum of three months;

- At the district level, the maximum storage time allowed is four months and the minimum is one month;

- At the SDP level, supplies may be stored for one month.

The prices of contraceptive products are set by the government of Senegal, including profit margins, for each level and sector.
Although this system ensures effective integration of FP products in the PNA system, it does have some drawbacks, including restrictions on storing FP products (since the PNA, PRAs, and districts have to store larger quantities of contraceptives.) Moreover, delays are often noted in the ordering of contraceptive products by the SDPs because profits from the sale of the contraceptives are used first to pay for the high SDP operating costs. Limited options for postpartum family planning are prominent among the numerous obstacles to widespread use of family planning in Nigeria.

\section{Commodity Security Issues}

In an effort to avoid supply chain difficulties and ensure the availability of contraceptive commodities for family planning programs, DSRSE has implemented a contraceptive security plan that focuses on: (1) capacitybuilding of logistics managers, (2) onsite training at governmental depots; (3) training of managers in $\mathrm{MOH}$ logistical management tools (Channel, Reality Check, Optimize); and (4) supportive supervision. In addition, the Informed Push Model was pilot tested with the collaboration of the ISSU project. This model rationalizes contraceptive distribution and management from the district to the regional level. Results from the pilot testing that took place in two districts (Pikine and Kaolack) revealed a significant decrease in the rate of contraceptive stockout ( $0 \%$ stockout), and better management of product ordering, which was facilitated by better data reporting (100\% of SDPs transmitted their data) . A scaling up of the model is planned by June 2013 in the three following regions (Dakar, Kaolack, and Thiès) by Initiative Sénégalaise de Santé Urbaine/Senegalese Urban Health Initiative (ISSU), after which the experience will be extended to the rest of the country in accordance with the National Action Plan for Family Planning implementation. This plan also emphasizes the integration of contraceptives into the drug quality control process as well as into a pharmaceutical supervision process (occurring on a quarterly basis).

\section{Regulatory Framework for New Contraceptives and Health Products}

The introduction of any new drug or product must follow the procedures of the Directorate of Pharmacy and Medicines (DPM). A permit and a Market Introduction Authorization (MIA) are required. To obtain these approvals, specific documentation is required 
on the product (specificity, safety, efficacy, characteristics, clinical trials, and results of acceptability study). However, for research purposes, approval from the National Ethics Committee for Health Research (CNERS) is sufficient. The study protocol should include information about the product (documentation of previous studies on safety, efficacy, where the product has been tested, findings of previous research, study areas, necessary amount of product to be used in the study). The approval from CNERS must be accompanied by a letter from the DSRSE addressed to the DPM requesting authorization to introduce the product. This procedure requires close monitoring on the part of the research team to prevent potential delays. In addition, customs clearance can be time-consuming and complex. Some stakeholders interviewed have suggested hiring an import consultant specializing in these issues, if necessary.

\section{EXPERIENCE OF CONTRACEPTIVE INTRODUCTION IN SENEGAL}

The government of Senegal is keen to expand the range of methods available to couples for achieving their reproductive health goals. The multiple examples of product introduction in the country can be considered positive indicators that there is indeed interest for new contraceptive products. Furthermore, both policymakers and development partners are interested in the introduction of new contraceptive methods. Stakeholders also show openness to new technologies, especially if these technologies are consistent with national policies and guidelines.

\section{"A broader range of methods will meet users' need better, particularly for women with unmet need."}

\section{Latest Contraceptive Methods in Introduction}

In the past few years and looking forward, several methods have been/will be pilot tested or studied for acceptability. Such experiences can serve as valuable groundwork for planning the introduction of the PVR. These include:

Introduction of Emergency Contraception (EC). Since 2000, the Population Council has supported the efforts of the Ministry of Health in the introduction of EC into the national FP program. These efforts have targeted both the public and private sectors and helped to officially include EC products in the range of national FP methods. EC products are now integrated into the Policies, Standards, and Protocols of FP services. The

\section{LATEST CONTRACEPTIVE} METHODS IN INTRODUCTION

- Emergency contraception

- Depo Provera IM (DMPA IM) at community level

- Acceptability of Depo-subQ Provera (aka Sayana Press)

- Implanon

- PVR

private sector is the preferred source of provision of EC because it offers privacy and is accessible to many segments of the population, despite higher prices. Meanwhile, supply through the public sector is low due to insufficient promotion and frequent expiration of products linked with slow demand. Furthermore, research indicates negative attitudes of providers about EC products, which do not favor their promotion. As a manager at the national level indicated "low demand of EC explains the expiry of 20,000 units of DUET bought with the national budget" (Population Council 2012). In addition, EC is poorly integrated into initial family planning counseling.

Administration of Depo Provera IM (DMPA IM) by Community Health Workers: In 2012, the Ministry of Health, with support from FHI360, Childfund, and 
CEFOREP, started pilot testing the introduction of DMPA IM by Community Health Workers in three districts (Joal, Dioffior, and Nioro) across three regions of Senegal. The study will continue until March 2013.

\section{Acceptability study of Depo-subQ Provera $104^{T M}$ in the Uniject system (also known as Sayana Press): In}

2012, the Ministry of Health began leading efforts for the introduction of Depo-subQ Provera $104^{\mathrm{TM}}$ in the Uniject system to Senegal, with support from PATH, FHI360, and CEFOREP (PATH 2012). The study has two components: an acceptability study and operations research. Working in three districts of the Thiès region (Mbour, Thiès, and Tivaouane), PATH leads the operations research and $\mathrm{FHI} 360$ is in charge of the acceptability studies. Enrollment for the acceptability study was completed at the end of 2012 for a three-month follow up.

Introduction of Implanon: As part of FP repositioning, the Ministry of Health is introducing Implanon. DSRSE has received part of the products from UNFPA, to be used for providers' training. Providers from the Dakar region were trained in 2012.

\section{Lessons Learned from Experiences of Contraceptive Introduction}

Based on these previous experiences, there are several key lessons learned:

- Early involvement of Ministry of Health Officials and advocacy with policymakers is essential for facilitating product introduction and ensuring proper ownership by national stakeholders; recourse to the contraceptive security technical committee offers an opportunity to obtain validation from the $\mathrm{MOH}$ and to contribute to their regular update during study implementation.

- Continuous communication with decisionmakers is useful in generating their support.

- It is important to foresee customs procedures to avoid delays in introducing the product in the country. The research team will need to ensure that all technical documents required for the approval are available in a timely manner. Stakeholders consulted strongly suggested that the firm that markets and promotes the product, Andromaco, be associated from the beginning to provide support and experience to the research team in the introductory phase.
Several tasks should be implemented differently from previous efforts to introduce new contraceptive products. Specifically, the Council must:

- Build sufficient time for national partners to provide ethical and technical reviews so as to ensure that introductory activities are conducted in a framework of voluntarism, choice, and rights.

- Integrate into the preparatory phase of the study lessons learned from previous experiences on contraceptive products introduction in Senegal.

- Promote the PVR as soon as possible in health services (such as at postnatal care, prenatal care, immunization services and maternity wards) so that women are familiar with it at the start of the study.

- Involve key stakeholders from the beginning.

Some of the resources that must be made available include:

- Relevant French literature on PVR.

- Providers' training in the use of PVR and management of side effects.

- Product documentation.

\section{SUPPORT FOR THE PVR}

The government of Senegal has been a strong supporter of the idea of introducing the PVR into health programs. That the vaginal ring offers new user-controlled opportunities for women would fit aptly into the political repositioning of FP adopted by the Ministry of Health in recent years.

This approach taken by the Ministry of Health is strongly supported by the development partners. As one of them indicated: "[The PVR] offers new opportunities and options to women." They also confirmed their willingness to support and collaborate with any project that is in line with government policy.

However, some partners pointed to "the need to respect the ethical rules that govern the provision of contraception, particularly in the immediate postpartum period" [a manager at the national level]. Communication efforts will be required to ensure that managers at all levels of the health system understand the method, how it fits in the current range of contraceptive methods available in Senegal, and when it can be provided to a woman. Other stakeholders suggested "anticipating supply problems that could arise from 
providing a wider range of methods (e.g. storage) and adjusting method mix to preferences by area" [a manager at the national level].

During consultation for the mapping exercise, several stakeholders indicated a positive attitude toward the PVR and believed that it could be introduced successfully in the mix of methods. Most stakeholders believed that the PVR could rise prominently in the range of contraceptive methods because of its innovative nature and the fact that it is more easily administered in health posts, as a method of family planning that requires minimal provider involvement. It could therefore be made more accessible to rural women than other long-acting methods which, until recently, were only available at health centers and hospitals. Such continued decentralization of product delivery could have a significant positive impact on current patterns of use.

Supportive stakeholders also raised several considerations:

- Possible reluctance about inserting the PVR into the vagina for women who do not like to touch their genitalia

- Husband's attitude

- Interference of the ring during sex

- Possible effects of vaginal douche (a common practice in Senegal) on ring efficacy

- Ring operating mode

- Management of side effects

- Potential expulsion of the ring;

- Suitability of the ring to all women

Despite the large interest in this new method, there are potential factors that could hinder PVR uptake, such as conservative opinions, negative rumors about the PVR and/or device-based modern contraception generally, gender issues, and decision processes.

\section{Sector of Introduction}

According to most stakeholders interviewed, the PVR could be introduced in both the public and private sectors. To achieve the goal of $27 \%$ prevalence rate targeted by the 2012-2015 Family Planning Action Plan, 125,000 of the 350,000 new clients to be recruited by 2015 will be enrolled by the public sector and 100,000 by the private sector. Some key stakeholders believe that the vaginal ring is also suitable for community- level introduction, with 125,000 new clients expected from this level.

\section{Communicating about the PVR}

Eighty-eight percent of households in Senegal have a mobile phone. Seventy-five percent own a radio, and $79 \%$ of urban and $26 \%$ of rural households have a television. However, in the months preceding the 2010-2011 DHS-MICS survey, 60\% of female and $49 \%$ of male respondents did not see, hear, or read a family planning message on the radio, television, or in a magazine or newspaper. Among women not currently using a contraceptive method, 89\% did not discuss family planning with a health worker, and only $6 \%$ had been visited by a fieldworker who discussed it. Among women who visited a health facility in the last 12 months, only $7 \%$ had discussed family planning with a health worker during their visit. This information clearly indicates that improved methods of communication are required for more women to become aware of and to utilize family planning methods.

Several avenues of information could be useful for developing and disseminating PVR messaging. An approach based on social marketing focusing on customer needs could effectively highlight the advantages of the product, such as efficacy, lack of interference with sexuality and breastfeeding, and its being usercontrolled. A community-based approach to awarenessraising and product provision could also be developed. On the whole, the integration of the PVR into the existing range of available contraceptive methods offered during initial counseling is a preferred way of establishing it in the existing family planning product mix. In addition, many stakeholders suggested that a good communication strategy be developed to increase public support for this product.

\section{CONCLUSIONS}

Senegal is a promising context for the introduction of the PVR. The government is committed to repositioning family planning and has created an enabling environment, with factors such as:

- The adoption of the 2005 Law on Reproductive Health that contributes to creating a legal environment conducive to family planning program initiatives; 
- The elaboration of a Strategic Plan for Reproductive Health which is similarly conducive and involves the private and nonprofit sectors as well as communitylevel actors as strategic sources for providing family planning;

- The elaboration and high visibility launch of the 2012-2015 Family Planning Action Plan;

- An effective family planning advocacy effort, which helps to mobilize public resources for the purchase of contraceptives;

- The improvement of service delivery through training of the majority of providers in contraceptive technologies;

- Task-shifting to head nurses, helping to strengthen accessibility to long-acting contraceptive methods at the peripheral level;

- The decentralization of service delivery at the community level, starting with the initial provision of oral contraceptive pills by matrons in heath huts, and current research on introduction of methods such as Uniject IM and Depo SubQ at community level;

- The strengthening of the logistics system through training of key staff in contraceptive logistics, supportive supervision, and testing of innovative approaches such as the Push Model; and

- Efforts to raise awareness of family planning at the community level by working with community-based organizations (Badien Gox, women's groups, religious networks).

There are also various encouraging socio-cultural trends which suggest the potential for acceptance of the PVR, including that:

- Birth spacing is already an accepted norm in Senegal, indicating that the PVR's status as a primarily postpartum family planning method could garner it more support among the general population;

- Over three quarters of both male and female respondents felt that religious leaders should speak more overtly about family planning.

However, based on the information gathered, input from the stakeholder interviews, and previous experiences of contraceptive introduction, some key accompanying measures will need to be taken to ensure proper execution of the acceptability study, including:
- Involve officials of the Ministry of Health early and thorough the process;

- Ensure that all documentation and paperwork required for the introduction of the product be completed before the research team engage introduction procedures;

- Develop and disseminate literature on the PVR and project in French as much as possible;

- Establish a strong and appropriate communication plan; and

- Establish a timely procurement system.

To address social resistance and perceived religious barriers to use of family planning, stakeholders indicate that the following efforts should be made:

- Disseminate the law on $\mathrm{RH}$;

- Involve more men in FP programs;

- Disseminate religious discourses on the position of Islam and Christian on FP; and

- Increase the involvement of community actors and journalists in communication about FP.

Some key stakeholders suggest that improving young people's access to services requires the following measures be taken:

- Implement suitable and appropriate channels of communication, including using ICTs;

- Strengthen youth RH education;

- Broaden the network of youth counseling centers, especially in rural areas; and

- Strengthen the capacity of providers to address the needs of this population.

The PVR has the capability of improving the family planning practices of postpartum women across a wide span of spatial, demographic, and socioeconomic settings. By extension, women's use of the ring can improve the health of her whole family. Its innovative, long-acting, user-controlled design will introduce a unique dimension to the currently available method mix and is a promising prospect for provision at the community level. If the acceptability study and subsequent introduction of the PVR are conducted with care and methodology, this method has a strong chance for success in Senegal. 


\section{LIST OF STAKEHOLDERS INTERVIEWED}

\begin{tabular}{|c|c|c|}
\hline Institutions & Persons contacted & Title \\
\hline \multirow{4}{*}{$\begin{array}{l}\text { Directorate of Reproductive Health } \\
\text { and Child Survival }\end{array}$} & Dr Bocar Daff & Director \\
\hline & Dr Ousseynou Faye & Head of Maternal Health Division \\
\hline & Dr Fatima Ndiaye & Head of Logistics \\
\hline & Mme Aissatou Sano Coly & Head of Family planning Division \\
\hline $\begin{array}{l}\text { Directorate of Pharmacy and Medi- } \\
\text { cines }\end{array}$ & Dr Rokhaya Kandé & Reproductive Health Administrator \\
\hline DANSE & Dr Aissatou DIOP & Chief of Division \\
\hline ADEMAS & Dr Serigne Momar Kane & Director of Research \\
\hline \multirow[t]{3}{*}{ ASBEF } & Dr Balla Moussa Diedhiou & Executive Director \\
\hline & Mr Moussa Mané & Program Director \\
\hline & Dr Binta Ndiaye & Clinical Coordinator \\
\hline CEFOREP & Mr Thierno Dieng & Coordinator \\
\hline Childfund & Mme Sébastiana Diatta & Reproductive Health Advisor \\
\hline FHI360/Progress & Dr Siga DIOP & $\begin{array}{l}\text { Research Associate (Progress Proj- } \\
\text { ect Administrator) }\end{array}$ \\
\hline IntraHealth & Mme Hawa Talla & Program Coordinator \\
\hline \multirow[t]{2}{*}{ Marie Stopes International } & Dr Maaike Van Minke & Country Director \\
\hline & Mme Colette Ndoye & Reproductive Health Advisor \\
\hline PATH & Dr Yakou Dieye & $\begin{array}{l}\text { Coordinator RH Program \& M\&E } \\
\text { Advisor }\end{array}$ \\
\hline Private Physician Association & Dr Manuel PINA & $\begin{array}{l}\text { Private Physician, Association } \\
\text { Member }\end{array}$ \\
\hline Religious Network (Islam) & Mr Ousmane Samb & Program Coordinator \\
\hline Senegalese Midwives Association & Mme Marieme Fall & President \\
\hline \multirow[t]{2}{*}{$\begin{array}{l}\text { Senegalese Urban Health Initiative } \\
\text { Project (ISSU) }\end{array}$} & Dr Fanding Badji & $\begin{array}{l}\text { Deputy Administrator/ Services } \\
\text { Supply }\end{array}$ \\
\hline & Mme Aminata Niang & Dakar City Coordinator \\
\hline Siggil Jiggen Network & Mme Fatou Ndiaye Turpin & Program Coordinator \\
\hline UNFPA & Dr Selly Kane & Reproductive Health Advisor \\
\hline \multirow[t]{2}{*}{ USAID } & Dr Amadou Mbow & Reproductive Health Advisor \\
\hline & Dr Ramatoulaye Dioum & Reproductive Health Advisor \\
\hline
\end{tabular}


ANSD (L'Agence Nationale de la Statistique and ICF International). 2012. 2010-11 Senegal Demographic and Health and Multiple Indicators Survey: Key Findings. Calverton, Maryland, USA: ANSD and ICF International.

Government of Senegal. 2012. Plan d'Action Nationale de Planification Familiale. 2012-2015. Dakar: Government of Senegal

- 2006. "Roadmap for accelerating the multi-sectoral fight against maternal and neonatal mortality, 20062015." Dakar: Government of Senegal.

—_. 2005. "Loi no 2005-18 du 5 août 2005 relatif à la santé de la reproduction." Dakar: Government of Senegal.

IntraHealth. July 2011. Maternal, Neonatal and Child Health Program - Endline report.

Intrahealth International. 2012. “2011 Baseline Survey for the Senegal Urban Health Initiative (ISSU) Household Survey: Final Report." Chapel Hill, NC.
ISSU, MLE, and IntraHealth. La planification familiale sauve des vies : initiative en sante santé de la reproduction en milieu urbain. <http://www.urbanreproductivehealth.org/sites/mle/files/Data_Handout_French_0. pdf>.

PATH. 2012. Etude opérationnelle : logistique de l'administration de depo-subQ dans le système d'injection Uniject au Sénégal et en Ouganda. Seattle: PATH. <http:// www.urbanreproductivehealth.org/sites/mle/files/ depo_operational_assessment_factsheet_mars2012_ french_a4_27-feb.pdf>.

Population Council. 2012. “Key opinions leaders' and providers' attitudes, beliefs, and practices about EC.” New York: Population Council.

Susheela Singh and Jacqueline E. Darroch. 2012. Adding it up: Costs and Benefits for Contraceptive Services. New York: Guttmacher, Institute and UNFPA. 